\title{
A Novel Minimum-Phase Dual-Inductor Hybrid Boost Converter with PWM Voltage-Mode Controller
}

\author{
Van Ha Nguyen ${ }^{\dagger}$, Abdul Hafiz Alameh ${ }^{\dagger}, \mathrm{Nam} \mathrm{Ly}^{\dagger}$, Yves Blaquière ${ }^{\dagger}$ and Glenn Cowan \\ ${ }^{\dagger}$ Department of Electrical Engineering, École de technologie supérieure (ÉTS), University of Quebec, Montreal, Quebec, Canada \\ ${ }^{*}$ Department of Department of Electrical and Computer Engineering, Concordia University, Montreal, Quebec, Canada \\ E-mail: van-ha.nguyen.1@ens.etsmtl.ca
}

\begin{abstract}
This paper presents a new dual-inductor hybrid boost converter (DI-HBOC) with two inductors located at the output. This structure allows continuous current delivered to the load, thus, reducing the output filtering capacitor size and the output voltage ripple. By relocating the inductor at the output, which is the lower current path, the conduction loss on the inductor can be significantly reduced. The right half plane zero (RHPZ) in the control-to-output transfer function can also be eliminated; therefore, a simple pulse-width modulation (PWM) voltage-mode controller can be used for the proposed DI-HBOC while still achieving high closed-loop bandwidth and fast transient response. The distinct features of the proposed converter are analytically demonstrated. A 12-to $24 \mathrm{~V}$ DI-HBOC and a conventional BOC (CBOC) using low- $R_{0 N}$ GaN switches with PWM voltage-mode controller are also implemented in PSIM for verification and comparison. The simulated peak power efficiency is $97.4 \%$ that is $1.17 \%$ higher than the CBOC. At 3 A load current, the power efficiency is improved by $9.7 \%$ and the output ripple is only $17.5 \mathrm{mV}, 6 \mathrm{x}$ lower than in CBOC.
\end{abstract}

Keywords - Step-up DC-DC converter, boost converter, hybrid DC-DC boost converter, low EMI boost converter, minimum-phase boost converter, voltage-mode control, GaN.

\section{INTRODUCTION}

Step-up converters have been widely used in various applications such as uninterruptible power supplies, LED drivers, backlit TV LCDs, flash LEDs and audio amplifiers [14]. Among three categories of DC-DC step-up converters shown in Fig. 1, the SC and VM converters are simple and can be fully integrated on-chip. But their conversion efficiency is low $(<85 \%)$, and the output power is also limited ( $\mathrm{mW}$ range). For moderate to high power applications, the conventional switched-inductor boost converter (CBOC) has dominated because of its higher power capability and power efficiency compared to SC and VM counterparts [5]. However, there remain four critical problems associated with the $\mathrm{CBOC}$, which are graphically summarized in Fig. 2 and explained as below:

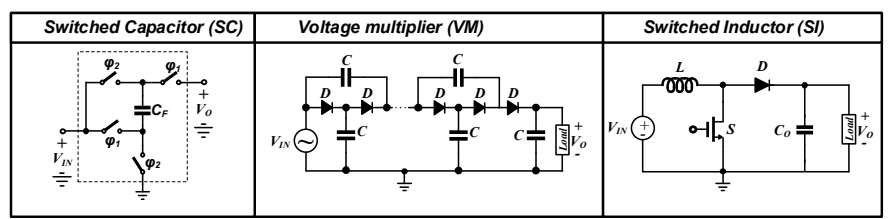

Fig. 1. Main types of step-up converter: Switched-capacitor (SC), Voltage multiplier (VM), Switched-inductor boost converter (SI).

First, the conduction loss is mainly contributed by $\mathrm{I}^{2} \mathrm{R}$ loss from direct current resistance (DCR) of the inductor, affecting the power efficiency and heat issue of CBOC. This is because (1) $\mathrm{R}_{\mathrm{ON}}$ of new-generation power switches (e.g. GaN HEMT
[6]) and the equivalent series resistance (ESR) of capacitors are generally much smaller than the DCR of the inductor, (2) inductor stays in the input, which is the high current path of the CBOC. Second, the output voltage ripple is high because the current supplied to the load is discontinuous, requiring a large filtering capacitance $\mathrm{C}_{\mathrm{O}}$ to achieve low output ripple. Third, output conducted electromagnetic interference (EMI) is high because of discontinuous critical current path, which results in the voltage spiking noise at the output as the converter output is directly tied to the switching node. Fourth, there exists a right half plane zero (RHPZ) in the control-to-output transfer function of the CBOC. This RHPZ is movable and can stay at low frequency at heavy load, limiting the bandwidth and transient response of the CBOC. As a result, complex currentmode control and sliding-mode control have been utilized to improve the converter's dynamic performance [7-8].

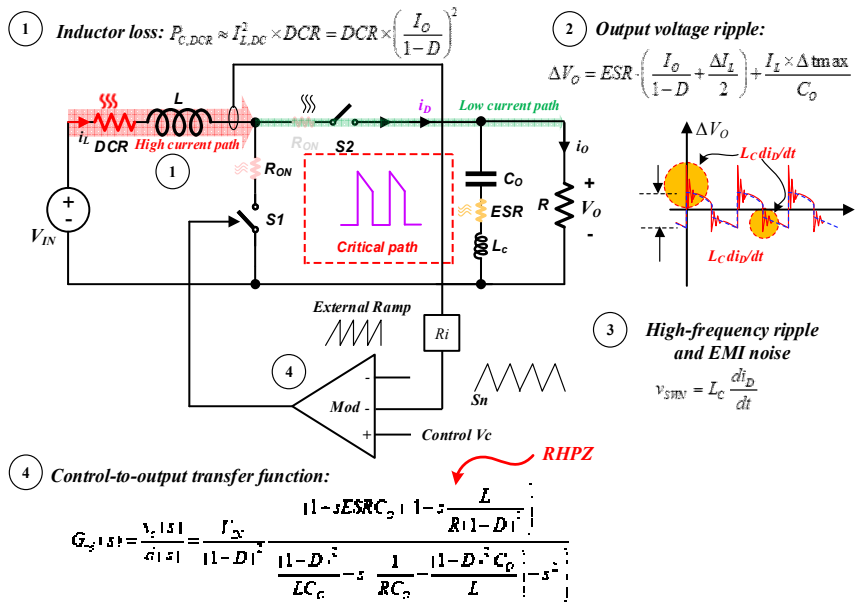

Fig. 2. Demerits of the CBOC: High $I^{2} R$ loss of the inductor, large output ripple, high EMI noise, complex controller.

Several key works have been reported to improve CBOC performance, mainly focused on enhancing the converter efficiency [9-12]. A KY boost converter is reported in [9] with its inductor moved from the input (high current path) to the output (low current path). This reduces DCR loss, eliminates pulsating output current, thereby reducing the output voltage ripple and output EMI noise. However, the voltage gain of this boost converter is limited at $1+2 \mathrm{D}$. The multi-phase boost converter reported in [10] can also reduce the conduction loss by splitting the current into many inductors, thereby reducing total DCR loss. Another solution is to use a multi-level boost converter (MBC) [11]. The idea is to reduce the voltage stress at the switching node of the inductor, thus, a smaller inductor with lower DCR can be used yielding higher efficiency and smaller converter size. In [12], a dual-path step-up converter 
(DPUC) was proposed. A capacitive path is added to share the delivered current to the output, thus reducing the inductor current and reducing the conduction loss of the inductor as well. In these boost converters, even the $I^{2} \mathrm{R}$ loss of the inductor can be reduced; however, other losses increase. The hard-charging loss occurs in most reported hybrid DC-DC converter designs [9-12]. The high amount of power switches and capacitors in these boost topologies also contributes extra loss. With the exception of the boost topology in [9], complex controllers are needed as the RHPZ still exists in the control-tooutput small-signal transfer function of these boost converters.

In light of these issues, this paper presents a novel dualinductor hybrid boost converter (DI-HBOC) that can improve concurrently four main problems that exist in the CBOC. The proposed DI-HBOC has: (1) high efficiency by reducing loss on the inductor without any hard-charging loss, (2) continuous input/output current which helps to reduce EMI and ripple at the output, (3) eliminate RHPZ in the small-signal transfer function that improves the converter's dynamic performance. Additionally, the voltage gain is similar to CBOC.

The paper is organized as follows: Section II analyses steady-state operation and loss of the DI-HBOC. Section III briefly presents small-signal analysis. Preliminary simulation results in PSIM are presented in Section IV. Section V ends the paper with some conclusions.

\section{PROPOSED DUAL-INDUCTOR HYBRID BOOST CONVERTER}

\subsection{Steady-state operation}

The structure of the proposed DI-HBOC consists of two switches $S 1, S 2$; two inductors $L_{1}, L_{2}$ and two capacitors $C_{\mathrm{F}}, C_{\mathrm{O}}$ (Fig. 3). The DI-HBOC operates in 2 phases as shown in Fig. 4 with the key waveforms shown in Fig. 5.

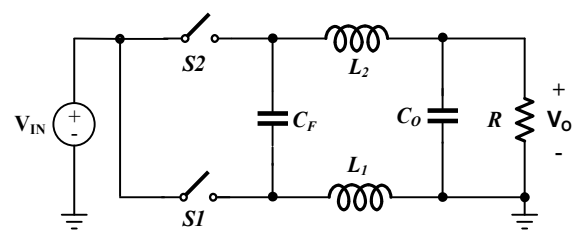

Fig. 3. Proposed dual-inductor hybrid boost converter.

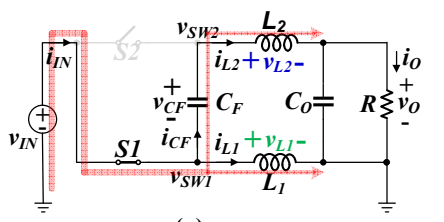

(a)

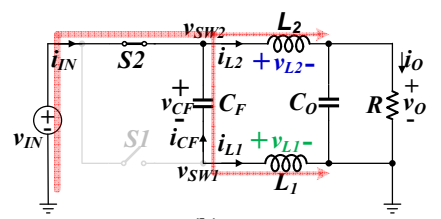

(b)
Fig. 4. Operation of the DI-HBOC: (a) Phase 1, (b) Phase 2.

Phase 1 (During DT): switch $S 1$ is turned $\mathrm{ON}$ and $S 2$ is turned OFF, the voltage across $L_{1}$ is the input voltage $v_{I N}$, the voltage across $L_{2}$ is the input voltage plus the voltage $v_{C F}$ across $\mathrm{C}_{\mathrm{F}}$ minus the output voltage $v_{O}$. Both $L_{1}$ and $L_{2}$ are magnetized. In this mode, $C_{\mathrm{F}}$ is discharged.

Phase 2 (During (1-D)T): as soon as $S 1$ is turned OFF and $S 2$ is turned $\mathrm{ON}$, the voltage across $L_{2}$ is $v_{I N}-v_{O}$, the voltage across $L_{1}$ is $v_{I N}-v_{C F}$. Both of $L_{1}$ and $L_{2}$ are demagnetized. In this mode, $C_{\mathrm{F}}$ is charged.
Based on the volt-second balance of the two inductors and capacitor-charge balance of the flying capacitor $C_{\mathrm{F}}$, the following key equations can be derived:

$$
M_{v}=\frac{V_{O}}{V_{I N}}=\frac{1}{1-D} ; V_{C F}=V_{O} ; i_{L 1}=\frac{D}{1-D} I_{O} ; i_{L 2}=I_{O}
$$

Clearly, the conversion gain of the proposed DI-HBOC is not limited as in $[1,3]$ and is similar to the CBOC design. As shown in Fig. 5, the flying capacitor $C_{\mathrm{F}}$ is charged/discharge by inductor currents $i_{\mathrm{L} 1}$ and $i_{\mathrm{L} 2}$. Soft switching can be achieved, reducing significantly the loss causes by the hard-charging effect that degrades power efficiency in various DC-DC hybrid converters [9-14]. Furthermore, since the output current is continuous, the conducted EMI is relaxed as compared to the CBOC design. The continuous output current also reduces the output filtering capacitor $\left(C_{\mathrm{O}}\right)$ size.

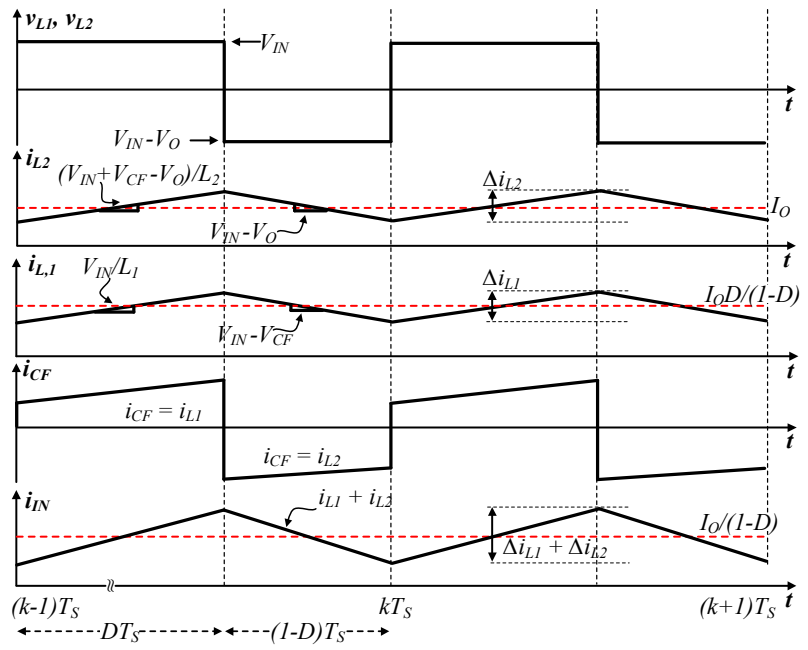

Fig. 5. Key waveforms in steady-state operation of DI-HBOC.

\subsection{Conduction loss analysis}

The DI-HBOC improves the power efficiency as compared to $\mathrm{CBOC}$ as a consequence of moving the inductor from highcurrent to lower current path. Without loss of generality, assume that $\Delta i_{\mathrm{L} 1,2}$ can be ignored, the on-resistance of the two switches are equal $\left(R_{\mathrm{ON}}\right)$ and inductor $L_{1}$ and $L_{2}$ are similar $\left(L_{1}=L_{2}, R_{\mathrm{L} 1}=R_{\mathrm{L} 2}\right)$. Also, it is assumed that the ESRs of $C_{\mathrm{F}}$ and $C_{\mathrm{O}}$ are small as compared to $R_{\mathrm{ON}}$ and the DCR of the power switches and inductors and can be neglected. With the support of Fig. 6, the conduction loss ratio between the proposed DI$\mathrm{HBOC}$ and $\mathrm{CBOC}$ can be easily derived as follows:

$$
\frac{P_{\mathrm{C}(\mathrm{DI}-\mathrm{HBOC})}}{P_{\mathrm{C}(\text { С } \mathrm{COC})}}=\frac{R_{O N}+D^{2} \times R_{L 1}+R_{L 2}(1-D)^{2}}{R_{O N}+R_{L}}
$$

For a fair comparison, assuming that two L1/L2 are connected in series to construct an equivalent inductor for CBOC; therefore, $L=2 \times L_{1}=2 \times L_{2}$ and $R_{\mathrm{L}}=2 \times R_{\mathrm{L} 1}=2 \times R_{\mathrm{L} 2}$. Fig. 7 shows the conduction loss ratio between the CBOC and the proposed DI-HBOC at different $R_{\mathrm{L}} / R_{\mathrm{ON}}$. Intuitively, the conduction loss is proportional to the resistance and the square of the current. Since the DI-HBOC has the inductor located at the low current path, its conduction loss can be less than that of the CBOC even though the DI-HBOC has same total DCR as shown in Fig. 7, leading to higher efficiency than the CBOC. 
The best conduction loss reduction can be achieved at $D=0.5$ and reduces when $D$ moves toward the two extremes $D=0$ and $D=1$. When $R_{\mathrm{L}} / R_{\mathrm{ON}}$ increases (i.e. lower $R_{\mathrm{ON}}$ switches are utilized), the proposed DI-HBOC becomes more efficient as the conduction loss is mainly contributed by inductors.

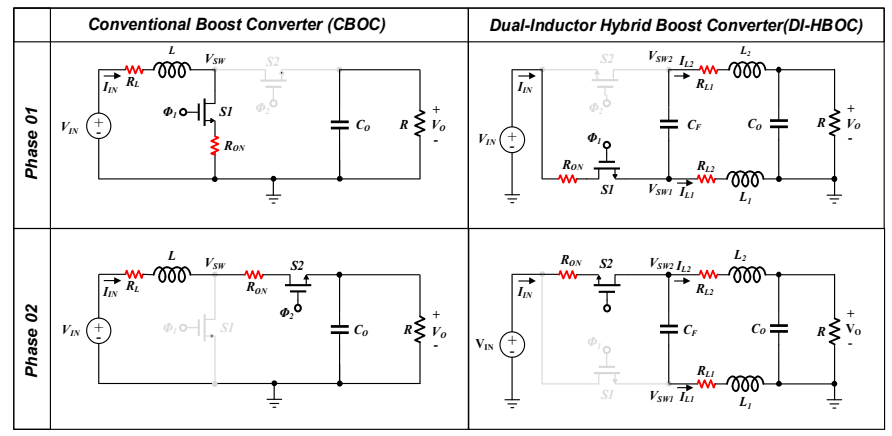

Fig. 6. Conduction loss analysis for comparison.

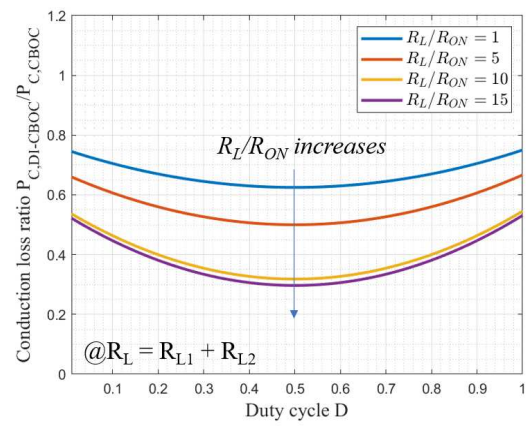

Fig. 7. Total conduction loss ratio between proposed DI-HBOC and CBOC under condition $\mathrm{R}_{\mathrm{L} 1}+\mathrm{R}_{\mathrm{L} 2}=\mathrm{R}_{\mathrm{L}}$.

\section{SMALL-SIGNAL MODEL OF PROPOSED DUAL-INDUCTOR HYBRID BOOST CONVERTER}

The small-signal model of the proposed DI-HBOC can be derived using the state space averaging (SSA) method [15]. A simple linear circuit can represent each of the two states where the switches in the circuit are replaced by their equivalent circuits during each state. Fig. 8(a) and (b) show the equivalent circuit corresponding to phase I and phase II operation, respectively. From these equivalent circuits, state equations for each phase can be derived. By applying the method presented in [13], the full control-to-output transfer function $G_{\mathrm{vd}}(\mathrm{s})$ of the DI-HBOC can be given by:

$$
G_{v d}(s)=\frac{v_{o}(s)}{d(s)}=G_{v d 0} \frac{\left(1+\frac{s}{\omega_{e s r}}\right)\left(1+\frac{s}{Q_{z} \omega_{z}}+\frac{s^{2}}{\omega_{z}^{2}}\right)}{\left(1+\frac{s}{Q_{p 1} \omega_{p 1}}+\frac{s^{2}}{\omega_{p 1}^{2}}\right)\left(1+\frac{s}{Q_{p 2} \omega_{p 2}}+\frac{s^{2}}{\omega_{p 2}^{2}}\right)}
$$

where:

$$
\begin{gathered}
G_{v d 0}=\frac{V_{I N}}{(1-D)^{4} R}\left((1-D)^{2} R-D R_{L}\right) \\
\omega_{e s r}=\frac{1}{R_{C} C_{O}} ; Q_{z} \omega_{z}=\left[\frac{C_{F} R R_{L}(1-D)-D L}{(1-D)^{2} R-D R_{L}}\right]^{-1} \\
\omega_{z}^{2}=\left[\frac{C_{F} L R(1-D)}{(1-D)^{2} R-D R_{L}}\right]^{-1}
\end{gathered}
$$

$$
\begin{gathered}
Q_{p 1} \omega_{p 1}=\left[\frac{\left(1-2 D+2 D^{2}\right) L+\left(C_{F}+C_{O}\left(1-2 D+2 D^{2}\right)\right) R R_{L}}{(1-D)^{2} R}\right]^{-1} \\
Q_{p 2} \omega_{p 2}=\left[\frac{C_{F} L\left(L-C_{O} L R+2 C_{O} R R_{L}\right)}{\left(1-2 D+2 D^{2}\right) L+\left(C_{F}+C_{O}\left(1-2 D+2 D^{2}\right)\right) R R_{L}}\right]^{-1} \\
\omega_{p 1}^{2}=\left[\frac{\left(C_{F}+C_{O}\left(1-2 D+2 D^{2}\right)\right) L}{(1-D)^{2}}\right]^{-1} ; \omega_{p 2}^{2}=\left[\frac{C_{F} C_{O} L}{C_{F}+C_{O}\left(1-2 D+2 D^{2}\right)}\right]^{-1} \\
\end{gathered}
$$

(b)

Fig. 8. Equivalent circuits for comprehensive small-signal analysis: (a) Phase 01, (b) Phase 02.

The transfer function of the power stage is a fourth-order system with two sets of complex-conjugate poles, a pair of complex-conjugate zeros and a zero produced by the ESR of the output capacitor. Close examination of the transfer function (3), along with (5) and (6) reveals all of its poles are located in the left half of the s-plane (LHP). However, its zeros can be either in the LHP or in the right half of the s-plane (RHP). The location of the zeros can be easily established by applying the Routh-Hurwitz criteria to the numerator polynomial of $G_{v d}(s)$ [16]. Here, the coefficient of $s^{2}$ is always positive, hence the remaining coefficient $1 / Q_{z} \omega_{z}$ defines the locations of the zeros. The necessary and sufficient condition to have all zeros in the LHP is $1 / Q_{z} \omega_{z}>0$, i.e. according to (5),

$$
C_{F}>\frac{D}{(1-D)} \frac{L}{R R_{L}}
$$
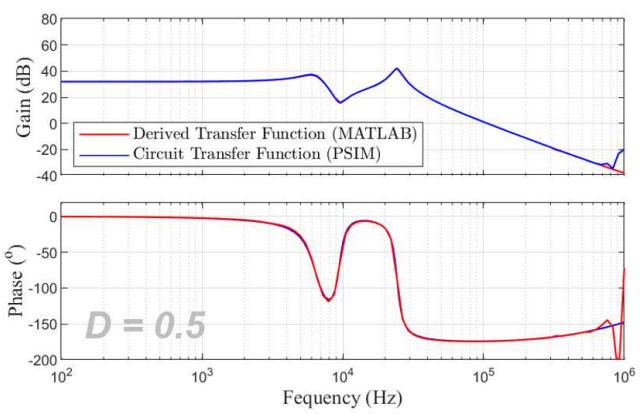

Fig. 9. Comparison between derived transfer function (MATLAB) and circuit transfer function (PSIM), @ $\mathrm{D}=0.5$.

By satisfying the relation in (10), the proposed DI-HBOC performs minimum phase (MP) characteristics, i.e. there are no RHPZ in the transfer function (3). As explained in Section I, MP enables the design of a boost converter with a conventional voltage-mode controller while still achieving a high bandwidth, speeding up the converter's response. Fig. 9 shows the Bode 
plot of the transfer function $G_{\mathrm{vd}}(\mathrm{s})$ of the DI-HBOC using circuit models in PSIM and a derived model in MATLAB. The high matching between them demonstrates that the derived analytical model fully describes small-signal properties of the real circuit model.

\section{Simulation of Voltage-Mode CONTROL Hybrid BOOST CONVERTER}

A $12 \mathrm{~V}$-to-24 V DI-HBOC was simulated in PSIM to verify its performance. The selected components used in PSIM are shown in Table I. The maximum load current is set at $I_{\mathrm{O}, \max }$ $=3 \mathrm{~A}$. Based on (10), the minimum value of flying capacitor is $22.94 \mu \mathrm{F}$. To ensure the zero stays in the LHP, $C_{\mathrm{F}}=40 \mu \mathrm{F}$ is selected. This also increases the damping factor caused by a pair of complex-conjugate LHP zeros which might reduce the gain of the DI-HBOC as shown in Fig. 9 (first valley).

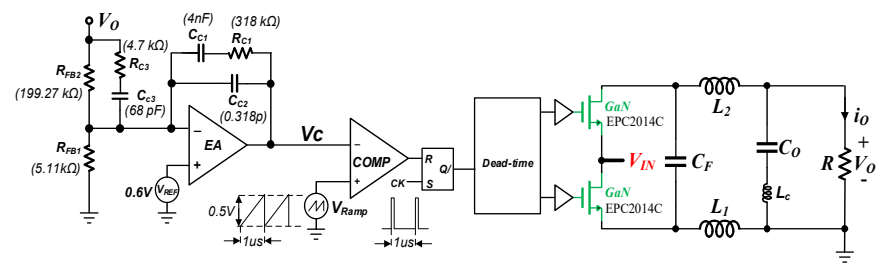

Fig. 10. Schematic of a 12 V-to-24 V DI-HBOC.

TABLE 1: CIRCUIT COMPONENTS AND VALUES.

\begin{tabular}{|c|c|c|}
\hline Component & Value & Unit \\
\hline$C_{\mathrm{O}}$ & $10 \mu \mathrm{F}, \mathrm{X} 7 \mathrm{R}, 1206$ & $1 \times 10 \mu \mathrm{F}$ \\
\hline$C_{\mathrm{F}}$ & $40 \mu \mathrm{F}, \mathrm{X} 7 \mathrm{R}, 1206$ & $4 \times 10 \mu \mathrm{F}$ \\
\hline$L_{1}, L_{2}$ & $20 \mu \mathrm{H}, \mathrm{DCR}: 109 \mathrm{~m} \Omega$, & $2 \times 20 \mu \mathrm{H}$ \\
\hline$S 1, S 2$ & $\begin{array}{c}\mathrm{EPC} 2014 \mathrm{C} \mathrm{GaN}[18] \\
\left(R_{\mathrm{ON}}\right)=16 \mathrm{~m} \Omega, V_{\mathrm{DS}, \max }=40 \mathrm{~V}\end{array}$ & 2 \\
\hline
\end{tabular}

As there is no RHP zero in the control-to-output transfer function of the DI-HBOC, a type III (PID) controller can be used to design a wide bandwidth closed-loop voltage-mode controlled DI-HBOC. The PID compensation network and the associated values are shown in Fig. 10 help to achieve $200 \mathrm{kHz}$ bandwidth at $1 \mathrm{MHz}$ switching frequency. Fig. 11 shows the load transient response of the proposed DI-HBOC with an overshoot of $123 \mathrm{mV}(5.1 \%)$ and a recovery times are within $30 \mu$ s when the load current steps down from $1 \mathrm{~A}$ to $0.5 \mathrm{~A}$. Fig. 12 shows the output voltage ripple $\Delta V_{\mathrm{O}}$ of the $\mathrm{CBOC}$ and DI-HBOC. It should be noted that for a fair comparison, $C_{\mathrm{O}, \mathrm{CBOC}}=50 \mu \mathrm{F}$ while $C_{\mathrm{F}, \mathrm{DI}-\mathrm{HBOC}}=40 \mu \mathrm{F}$ and $C_{\mathrm{O}, \mathrm{DI}-\mathrm{HBOC}}$ $=10 \mu \mathrm{F}$ (same total capacitance). A parasitic inductance $L_{\mathrm{C}}=50 \mathrm{pH}$ of output capacitor $C_{\mathrm{O}, \mathrm{CBOC}} / C_{\mathrm{F}, \mathrm{DI}-\mathrm{HBOC}}$ was added to examine high-frequency noise at the output. For the worse case at $I_{\text {load,max }}=3 \mathrm{~A}, \Delta V_{\mathrm{O}, \mathrm{DI}-\mathrm{HBOC}}$ is only $17.5 \mathrm{mV}$, compared to $105 \mathrm{mV}$ for $\Delta V_{\mathrm{O}, \mathrm{Cвос}}$. Also, the spiking noise appears in the output of CBOC with a peak-peak value of up to $129 \mathrm{mV}$ while it is absent for the case of DI-HBOC; thus, conducted EMI at the output of the DI-HBOC can be lower. Fig. 13 compares the simulated power efficiency of the CBOC and DI-HBOC with the setup $L_{1} / L_{2}=20 \mu \mathrm{H}, R_{\mathrm{L} 1} / R_{\mathrm{L} 2}=109 \mathrm{~m} \Omega, L=2 \times L_{1}, R_{\mathrm{L}}=$ $2 \times R_{\mathrm{L} 1}$, in which the calculated switching losses are also included based on [17] using GaN parameters [18]. At light load $I_{0}=0.15 \mathrm{~A}$, the efficiency is slightly improved by $0.32 \%$ while at heavy load $I_{0}=3 \mathrm{~A}$, the efficiency is significantly improved by $9.7 \%$. As the load increases, efficiency improvement is even more significant. The peak efficiency of the DI-HBOC $(97.39 \%)$ is $1.17 \%$ higher than of the CBOC $(96.21 \%)$. Furthermore, if $L_{1}$ and $L_{2}$ are coupled, effective $L_{1}$ and $L_{2}$ increase, current ripples $\Delta i_{\mathrm{L} 1,2}$ and $\Delta i_{\mathrm{SW}}$ on $L_{1} / L_{2}$ and $S_{1} / S_{2}$ decrease; thus, reducing the associated ac losses on $L_{1} / L_{2}$ and $S_{1} / S_{2}$. This scheme can further increase the power efficiency. Fig. 13 also shows the power efficiency of the uncoupled DIHBOC ( $L_{1}$ and $L_{2}$ are uncoupled, i.e. $L_{1} / L_{2}=20 \mu \mathrm{H}$ ), and a coupled DI-HBOC ( $L_{1}$ and $L_{2}$ are coupled with a coupling factor $=1$, i.e. $\left.L_{1, \text { eff }} / L_{2, \text { eff }}=40 \mu \mathrm{H}\right)$. The power efficiency difference is very small, meaning that ac losses are low and can be excluded from the analysis as assumed in Section II.

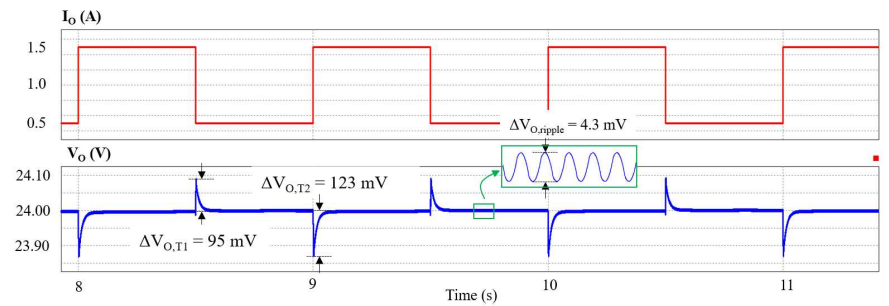

Fig. 11. Transient response of DI-HBOC using voltage mode controller $\left(@ V_{\mathrm{IN}}=12 \mathrm{~V}, V_{\mathrm{O}}=24 \mathrm{~V}, I_{\mathrm{O}, \mathrm{STEP}}=0.5 \mathrm{~A}\right)$.

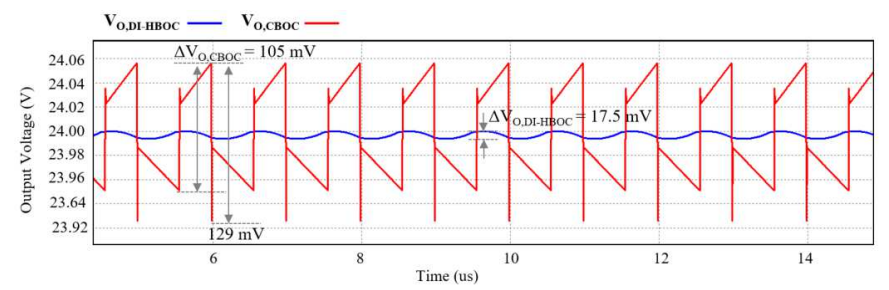

Fig. 12. Output ripple of CBOC and DI-HBOC at $I_{\mathrm{O}}=3 \mathrm{~A}$.

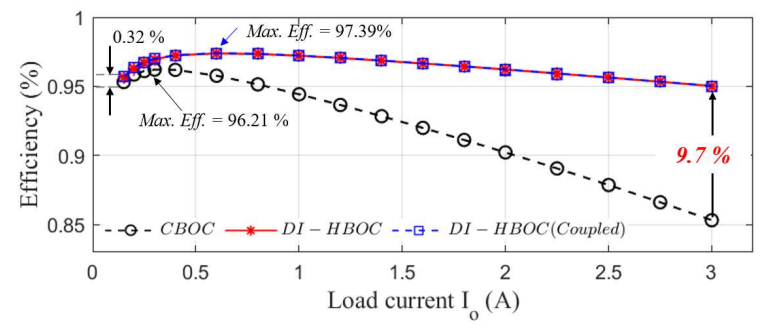

Fig. 13. Simulated power efficiency of DI-HBOC and CBOC at different load currents (without switching losses of $\mathrm{GaN}$ switches).

\section{CONCLUSIONS}

This paper has described a novel boost converter that provides the various attractive features to compete to existed step-up converters in terms of power efficiency, output ripple, EMI noise and dynamic response with a cost of using two separated inductors. The theoretical analysis and simulation results partially confirm the claimed merits of the proposed DIHBOC. To demonstrate the superiority of the proposed DIHBOC in terms of power efficiency, EMI, output ripple and dynamic response, measurement results will be implemented in our future work.

\section{ACKNOWLEDGMENT}

This work was supported in part by the Natural Sciences and Engineering Research Council of Canada (NSERC). 


\section{REFERENCES}

[1] Z. Chao, G. Zhang, and Z. Jiang, "A directly digital dual-loop controller design of boost converter for UPS applications", in Proc. IEEE Conference and Expo Transportation Electrification Asia-Pacific (ITEC Asia-Pacific), pp. 1 - 4, Sept. 2014.

[2] D. O. Bamgboje, W. Harmon, M. Tahan, and T. Hu, "Low-cost highperformance LED driver based on a self-oscillating boost converter", IEEE Trans. Power Electron., vol. 34, no. 10, pp. 10021 -10034, Jan. 2019.

[3] H.-C. Kim, C. S. Yoon, D.-K. Jeong, and J. Kim, "A single-inductor, multiple-channel current-balancing LED driver for display backlight applications", IEEE Trans. Ind. Appl., vol. 50, no. 6, pp. 4077 - 4081, Nov./-Dec. 2014.

[4] M. Berkhout, L. Dooper, B. Krabbenborg, and J. Somberg, "A $4 \Omega$; $2.65 \mathrm{~W}$ class-D audio amplifier with embedded DC-DC boost converter, current sensing ADC and DSP for adaptive speaker protection," IEEE J. Solid-State Circuits, vol. 48, no. 12, pp. 2952 - 2961, Dec. 2013.

[5] M. K. Kazimierczuk, "Pulse width modulated DC-DC power converters", $2^{\text {nd }}$ Ed., Wiley, 2016.

[6] A. Lidow, J. Strydom, M. D. Rooij, D. Reusch, "GaN transistors for efficient power conversion", $2^{\text {nd }} E d ., 2014$.

[7] C.-Y. Chan, S. H. Chincholkar, and W. Jiang, "Adaptive current-mode control of a high step-up DC-DC converter", IEEE Trans. Power Electron., vol. 32, no. 9, pp. 7297 - 7305, Sept. 2017.

[8] S. H. Chincholkar, W. Jiang, and C.-Y. Chan, "An improved PWMbased sliding-mode controller for a DC-DC cascade boost converter", IEEE Trans. Circuits Syst. II, Exp. Briefs, vol. 65, no. 11, pp. 1639 - 1643, Nov. 2018

[9] K. I. Hwu and Y. T. Yau, "KY converter and its derivatives", IEEE Trans. Power Electron., vol. 24, no. 1, pp. 128 - 137, Jan. 2009.

[10] D. Baba, "Under the hood of a multiphase synchronous rectified boost converter", Texas Instruments, 2014.

[11] J.C. Rosas-Caro et al., "A DC-DC multilevel boost converter", IET Power Electron., vol. 3, no. 1, pp. 129 - 137, Jun. 2008.

[12] S.-U. Shin, S.-W. Hong, H.-M. Lee, and G.-H. Cho, "High-efficiency hybrid dual-path step-up DC-DC converter with continuous outputcurrent delivery for low output voltage ripple", IEEE Trans. Power Electron., vol. 35, no. 6, pp. 6025 - 6038, Jun. 2020.

[13] G.-S. Seo and H.-P. Le, "S-hybrid step-down DC-DC converter-analysis of operation and design considerations", IEEE Trans. Ind. Electron., vol. 67, no. 1, pp. 265 - 275, Jan. 2020.

[14] Y. Huh, S. W. Hong, and G. H. Cho, "A hybrid structure dual-path stepdown converter with $96.2 \%$ peak efficiency using $250-\mathrm{m} \Omega$ large-DCR inductor", IEEE J. Solid-State Circuits, vol. 54, no. 4, pp. 959 - 967, Apr. 2019.

[15] R. W. Erickson and D. Maksimovic, "Fundamentals of power electronics", Norwell, MA, USA: Kluwer, 2001.

[16] M. Veerachary, "Analysis of minimum-phase fourth-order buck DC-DC converter", IEEE Trans. Ind. Electron., vol. 63, no. 1, pp. 144 - 154, Jan. 2016.

[17] Rohm semiconductor, "Switching regulator IC series: Efficiency of Buck Converter", Application Note, pp. 1-15, Dec. 2016.

[18] Efficient Power Conversion Corporation, "EPC2014C - Enhancement Mode Power Transistor", eGaN FET Datasheet, pp. 1 - 6, Aug. 2019. 